\section{Psychological impact of stillbirth on fathers}

\section{in the subsequent pregnancy and puerperium}

\author{
PENELOPE TURTON, WILLIAM BADENHORST, PATRICIA HUGHES, \\ JULIA WARD, SAMANTHA RICHES and SARAH WHITE
}

\begin{abstract}
Background Approximately I in 200 UK pregnancies ends in stillbirth. Although serious psychological effects of stillbirth on mothers are well established, much less is known about the impact of such loss on fathers.
\end{abstract}

\begin{abstract}
Aims To assess the psychological morbidity of fathers in the pregnancy and post-partum year subsequent to a stillbirth, to test within-couple effects and to identify risk factors.
\end{abstract}

Method This was a community-based cohort study of 38 pregnant couples whose previous pregnancy had ended in stillbirth, and 38 pair-matched controls. Psychological assessments took place antenatally and at 6 weeks, 6 months and I year postnatally.

\section{Results Fathers in the index group experienced significant levels of anxiety and post-traumatic stress disorder antenatally, but all of their symptoms remitted postnatally (after the birth of a live baby). Fathers' symptom levels were lower than those of mothers at all time points. In contrast to mothers, fathers experienced greater anxiety when a subsequent pregnancy (following stillbirth) was delayed.}

\section{Conclusions The vulnerability of fathers to psychological distress during the pregnancy after a stillbirth needs to be recognised.}

\section{Declaration of interest None.}

Much research on the psychological impact of perinatal loss on mothers has been published and widely disseminated over the past 30 years. Recent studies by our research group on the impact of stillbirth on mothers, using a case-control community-based sample, have established that stillbirth is a significant risk factor for depression and anxiety when assessed during a subsequent pregnancy and puerperium (Hughes et al, 1999). These studies have identified stillbirth as a category A event for the development of posttraumatic stress disorder (PTSD) in mothers (Turton et al, 2001). Much less is known about the impact of this relatively common trauma on fathers. This is perhaps not surprising, given the traditionally more peripheral role of men in the upbringing of children. However, social attitudes are changing, and today's father is expected to love and cherish his children, and to take an active part in their care.

This paper reports a systematic investigation of the psychological effects of stillbirth on fathers, and aims to address some of the limitations of the existing literature. We have restricted our focus to a specific type of loss, namely stillbirth, to avoid conflation with other pregnancy or child losses. We assessed parents in the pregnancy following a stillbirth, as we had postulated that this would be a reactivating stressor for all parents, irrespective of the time that had elapsed since their loss.

\section{METHOD}

\section{Procedure}

The local ethics committees granted approval of the procedure. To ensure that the study sample was drawn from a representative community-based population, participants were identified by screening consecutive case records in the antenatal clinics of three district general hospitals over a 3-year period. Using antenatal records, progress in pregnancy was monitored to ensure that the pregnancy was healthy and proceeding well. A letter describing the study and inviting couples to participate was sent during the third trimester of pregnancy. This was followed up by a telephone call 2 weeks later. The first interviews took place between 32 and 38 weeks' gestation, either in the hospital out-patient department or in participants' own homes. Follow-up interviews took place in participants' own homes.

\section{Assessments \\ Antenatal (third-trimester) assessment (current successful pregnancy)}

Observer-rated questionnaire in two parts. The first part of the questionnaire elicited the parents' socio-economic and medical history (age, ethnicity, level of education, employment status, income, obstetric history, history of previous physical and mental illness). The second part focused on the stillbirth (gestational age, time since the loss, level of family and partner support, clinical and social management of the stillbirth).

Assessment of depression. Depression in fathers was assessed with the Beck Depression Inventory (BDI; Beck et al, 1961), using the conventional cut-off score of $10 /$ 11 (Metcalfe \& Goldman, 1965).

Depression in mothers was assessed by means of the Edinburgh Postnatal Depression Scale (EPDS; Cox et al, 1987), a 10item self-report scale that was developed and validated to assess postnatal depression, and which is extensively used in the UK. The instrument has now been validated for use during pregnancy (Murray \& Cox, 1990), employing a cut-off score of $14 / 15$ for dichotomous analysis because of the high levels of dysphoria that occur in pregnancy.

Assessment of anxiety. The Spielberger State-Trait Inventory (Spielberger et al, 1970) was used. This 40 -item questionnaire measures anxiety at the time of testing (state) and general tendency to anxiety (trait).

Assessment of PTSD. The PTSD-I Interview (Watson et al, 1991) was used. This interview shows close correspondence with DSM-III-R (American Psychiatric Association, 1987) standards and correlates strongly with parallel Diagnostic Interview 
Schedule criteria and with the PTSD subscale of the Minnesota Multiphasic Personality Inventory (MMPI; Keane et al, 1984). The PTSD-I Interview has been shown to have substantial reliability and validity, with very high internal consistency and test-retest reliability. It provides binary present/absent and continuous severity/ frequency outputs on each symptom and symptom cluster, and on the entire syndrome.

Assessment of marital satisfaction. The Golombok Rust Inventory of Marital Satisfaction (GRIMS; Rust et al, 1988) was used.

\section{Assessment 6 weeks and 6 months after a recent successful pregnancy}

The following instruments were used:

(a) measures for assessment of depression (as above, except that in the case of the EPDS the conventional postnatal cut-off score of 12/13 was used for dichotomous analysis);

(b) the Spielberger State-Trait Inventory;

(c) the PTSD-I Interview.

\section{Assessment 12 months after a recent successful pregnancy}

The following instruments were used

(a) the BDI (in both mothers and fathers, because the EPDS is only validated up to 6 months post-partum);

(b) the Spielberger State-Trait Inventory;

(c) the PTSD-I Interview;

(d) the GRIMS

\section{Analysis}

All analyses were performed using the Statistical Package for the Social Sciences version 10.0 for Windows and SAS version 8.1 for SunOS. In univariate analyses the $\chi^{2}$-test or Fisher's exact test was used to look for associations between two categorical variables. Independent-samples $t$-tests were used to compare the mean scores between two groups, and Pearson correlations were used to look for an association between two continuous variables. Paired $t$-tests were used for the within-couple analysis.

Mixed models (using PROC MIXED in SAS) were employed to investigate depression and anxiety scores for all assessments, examining whether they differed between the index and control groups (group effects), whether they changed over time (time effects), or whether there was a group $\times$ time interaction (where any difference between the groups is not constant over time). This methodology was used so that all of the data collected could be utilised. More standard methods such as repeated-measures analysis of variance would have deleted a participant from the analysis if they had data missing for any assessment. This does not occur in PROC MIXED.

Multivariate analysis of variance (MANOVA) was used to ascertain what factors (all dichotomous) were associated with psychological morbidity (depression, state and trait anxiety and PTSD symptom severity) at the antenatal assessment in the index group of fathers.

\section{Recruitment of the index group}

Of 105 mothers who appeared to meet the study criteria on the basis of screening of case records, 16 mothers were subsequently excluded because we found that they had started a relationship with a new partner since the stillbirth. In the case of a further 16 couples the baby was born before they could be interviewed antenatally, either because the birth occurred a few weeks early, or because of difficulty in arranging a meeting. We excluded these couples because important baseline data would be missing. However, towards the end of the recruitment period, when the difficulty in enrolling couples who met the study criteria was more fully appreciated, the inclusion criteria were relaxed and we decided to include data for four couples who asked to be interviewed only after the safe arrival of their baby. Another 32 couples declined to participate, more often owing to refusal by the father than by the mother. Three couples proved impossible to contact despite repeated efforts.

A total of 38 couples $(52.1 \%$ of the 73 couples who were not excluded) had an initial assessment, of whom 34 were interviewed during pregnancy and 4 had their initial assessment postnatally. In total, 15 stillborn infants $(40.5 \%)$ had been born in the second trimester (20-27 weeks, mean gestational age 21.8 weeks) and 23 $(59.5 \%)$ had been born in the third trimester (28-41 weeks, mean gestational age 35.8 weeks). The time lapse between stillbirth and the expected date of delivery ranged from 11 to 44 months (mean=18.8,
18.8, s.d.=8.7). In total, 26 mothers $(68.4 \%)$ conceived within 1 year of a stillbirth.

Subsequent to the initial assessment, 1 couple was excluded because the mother had another stillbirth, 2 couples dropped out and attributed this to major marital difficulties, 2 couples moved abroad and 1 couple dropped out without giving a reason. We here report the 6-week followup data for 35 couples, the 6-month follow-up data for 33 couples and the 1-year follow-up data for 32 couples.

\section{Recruitment of the control group}

In total, 110 couples were matched from antenatal records to the index group. Of these, 51 couples $(46.4 \%)$ consented to participate in the study but, as with the index group, some couples (13 in total) had their baby before they could be interviewed antenatally, and were therefore excluded. A total of 38 couples $(39.2 \%$ of the 97 couples who were not excluded) entered the study, 43 couples declined to take part and 16 couples proved impossible to contact despite repeated efforts. Again it was nearly always the fathers who refused to take part in the study or were impossible to contact.

Subsequent to the antenatal assessment, one couple dropped out before the 6-month assessment without giving a reason. At the 6-week assessment data were not available for one family because the baby was ill and the family did not want a visit, and at the 6-month assessment data were unavailable for another family who refused a visit because they were moving house. We here report the 6-week follow-up data for 37 couples, the 6-month follow-up data for 36 couples and the 1-year follow-up data for 37 couples.

\section{RESULTS}

\section{Demographic characteristics of the sample}

The demographic data for the sample are shown in Table 1. This demonstrates that the index and control groups were well matched, as none of the data show significant differences between the index and control participants, with the exception of the fact that index group couples had a significantly lower combined gross annual income $(P=0.017)$. Although overall the socioeconomic status of the study population was considerably above the national 
Table I Demographic data for index and control groups

\begin{tabular}{|c|c|c|}
\hline & Index group & Control group \\
\hline \multicolumn{3}{|l|}{ Age, years: mean (s.d.) } \\
\hline Total & $33.75(4.89)$ & $34.33(4.70)$ \\
\hline Fathers & $34.84(5.04)$ & $35.58(4.57)$ \\
\hline Mothers & $32.66(4.55)$ & $33.08(4.55)$ \\
\hline \multicolumn{3}{|l|}{ Obstetric history, $n$ (\%) } \\
\hline Previous miscarriage (mother) & $13(34.2)$ & $13(34.2)$ \\
\hline Previous TOP (mother) & 3 (7.9) & $2(5.3)$ \\
\hline Live children - fathers & $13(34.2)$ & $18(47.4)$ \\
\hline Live children - mothers & $14(36.8)$ & $15(39.5)$ \\
\hline \multicolumn{3}{|l|}{ Level of education, $n(\%)$} \\
\hline No examinations & 0 & $3(3.9)$ \\
\hline ‘O’ level & $17(22.4)$ & II (14.5) \\
\hline 'A' level & $20(26.3)$ & $18(23.7)$ \\
\hline University & $39(51.3)$ & $44(57.9)$ \\
\hline \multicolumn{3}{|l|}{ Ethnicity, $n(\%)$} \\
\hline White & $55(72.4)$ & $58(76.3)$ \\
\hline African-Caribbean & $2(2.6)$ & $4(5.3)$ \\
\hline Indian/Pakistani/Sri Lankan & $8(10.5)$ & $10(13.2)$ \\
\hline African & $9(11.8)$ & $4(5.3)$ \\
\hline Other & $2(2.6)$ & 0 \\
\hline Involuntary unemployment $>3$ months, $n$ (\%) & 3 (3.9) & $4(5.3)$ \\
\hline Mean gross combined annual income, $£$ & 45000 & 64000 \\
\hline Gross combined annual income $\leqslant £ 20000, n(\%)$ & $15(19.7)$ & $9(I 1.8)$ \\
\hline Gross combined annual income below national average, $n(\%)$ & $24(31.6)$ & $17(23.0)$ \\
\hline History of serious physical illness', $n$ (\%) & $7(9.2)$ & $2(2.6)$ \\
\hline History of treatment for psychological symptoms ${ }^{2}, n(\%)$ & $18(23.7)$ & II (14.5) \\
\hline
\end{tabular}

TOP, termination of pregnancy.

I. Serious physical illness constituted an acute episode of illness that required in-patient treatment, or chronic disease (e.g. diabetes, kidney disease, tuberculosis) that required out-patient treatment.

2. Active treatment from general practitioner, or as an out-patient or in-patient. In the index group, at least one of these treatment episodes was related to the stillbirth in 15 out of 18 individuals. average in terms of both education and income, there was no significant difference between the index and control couples in the proportion of families whose annual income was below the national household average ( $£ 29000$; CACI, 2003), or who might be considered economically disadvantaged because they had a relatively low combined annual income $(\leqslant £ 20000)$.

\section{Representativeness of the sample}

Only limited data from antenatal records (for maternal age, ethnicity, gestation of lost baby and the presence of live children in the family) were available for those couples who refused to take part in the study or who did not meet the inclusion criteria. We found that among the couples who refused to take part or who were excluded the mothers were slightly younger (mean age $30.0 v .32 .7$ years; $t_{112}=2.308$, $P=0.023)$ and were significantly more
Data on income and education for couples who refused to take part in the study were insufficiently complete to allow valid comparisons.

\section{Rates of psychological symptoms in fathers}

Table 2 shows that fathers in the index group experienced higher levels of depression than controls across all assessments (except for the mean score at the 6-week follow-up, which was fractionally higher in the control group). However, the mixed-model analysis did not show a significant effect of group $\left(F_{73}=0.42\right.$, $P=0.517)$, although there was a significant time effect $\left(F_{60}=3.36, \quad P=0.025\right)$, with levels of depression falling postnatally. At the antenatal assessment, 5 out of 34 men $(14.7 \%)$ in the index group compared with 2 out of 36 men $(5.6 \%)$ in the control group reached case threshold levels for depression (Fisher's exact test: $P=0.253$ ). These rates fell to $3(9.7 \%)$ v. $2(5.9 \%)$ by the 1 -year follow-up. For both anxiety outcomes there were significant group (state: $\quad F_{73}=5.28, \quad P=0.024 ; \quad$ trait: $F_{73}=5.45, \quad P=0.022$ ) and time (state: $F_{65}=8.20, \quad P=0.006 ; \quad$ trait: $\quad F_{62}=5.35$, $P=0.024)$ effects, indicating that levels of anxiety differed both between the groups and over time. For state anxiety there was also evidence of a group $\times$ time interaction $\left(F_{65}=5.50, P=0.022\right)$ (i.e. the difference between the two groups was not constant over the two assessment times).

\section{PTSD}

We cannot report group effects for stillbirth-related PTSD because the control group had not experienced comparable trauma. However, we have already established that stillbirth is a category A stressor
Table 2 Levels of depression and anxiety in fathers group $\left(60.3 \% v .27 .6 \% ; \chi^{2}\right.$ test: $\left.P=0.001\right)$ There were no significant differences with regard to the presence of children in the family, problem pregnancies other than stillbirth, or gestation of lost pregnancy.

\begin{tabular}{|c|c|c|c|c|c|c|c|c|c|c|}
\hline \multirow[t]{3}{*}{ Outcome } & \multirow[t]{3}{*}{ Group } & \multirow[t]{3}{*}{$n$} & \multicolumn{8}{|c|}{ Assessment } \\
\hline & & & \multicolumn{2}{|c|}{ Antenatal } & \multicolumn{2}{|c|}{6 weeks } & \multicolumn{2}{|c|}{6 months } & \multicolumn{2}{|c|}{ I year } \\
\hline & & & Mean & s.d. & Mean & s.d. & Mean & s.d. & Mean & s.d. \\
\hline \multirow[t]{2}{*}{ BDI score } & Index & 34 & 6.06 & 6.55 & 3.69 & 3.76 & 4.24 & 8.94 & 4.42 & 4.79 \\
\hline & Control & 36 & 4.17 & 4.10 & 4.28 & 5.19 & 3.71 & 4.62 & 3.56 & 3.39 \\
\hline Spielberger state & Index & 35 & 36.97 & 11.69 & \multirow{2}{*}{\multicolumn{2}{|c|}{ NA }} & \multirow{2}{*}{\multicolumn{2}{|c|}{ NA }} & 31.32 & 9.36 \\
\hline score & Control & 37 & 30.16 & 6.83 & & & & & 29.17 & 8.87 \\
\hline Spielberger trait & Index & 34 & 37.97 & 9.68 & \multirow{2}{*}{\multicolumn{2}{|c|}{ NA }} & \multirow{2}{*}{\multicolumn{2}{|c|}{ NA }} & 34.68 & 10.09 \\
\hline score & Control & 37 & 32.81 & 6.72 & & & & & 30.91 & 8.31 \\
\hline
\end{tabular}

BDI, Beck Depression Inventory; NA, not available. 
for PTSD in mothers, and that mothers experience high levels of PTSD in the pregnancy subsequent to a stillbirth (Turton $e t$ al, 2001). We found similar levels of stillbirth-related PTSD in fathers. At the antenatal assessment, five fathers $(15.6 \%)$ met the criteria for a current diagnosis of PTSD, and six fathers $(18.8 \%)$ met the criteria for a lifetime diagnosis. As was found for mothers, PTSD symptoms remitted rapidly after the birth of a live baby. At the 6-week post-partum assessment, none of the fathers still had case-level symptoms, and this remained true at all of the remaining assessments.

We also assessed PTSD in relation to other stressors in all of the participants. With regard to non-stillbirth-related trauma, there was no difference between the groups in the prevalence of PTSD (lifetime or current) or in the overall symptom severity score. Only one father in the control group and none of the fathers in the index group reached case threshold level at the antenatal assessment, and none of the fathers in either group reached case threshold level at the 1-year assessment.

\section{Fathers' marital satisfaction}

Two couples in the index group dropped out during the course of the study and cited marital difficulties as a reason for this, whereas none of the control couples dropped out for this reason. However, there was no real evidence of a higher prevalence of marital problems in the index group. Although fathers in the index group had a slightly higher mean score on the GRIMS (indicating lower levels of marital satisfaction) at both the antenatal assessment and the 1-year post-partum assessment, these differences were not significant, and the scores generally indicated high levels of marital satisfaction.

\section{Fathers' coping strategies}

Fathers retrospectively reported that they had used various coping strategies to try to come to terms with their loss. Out of the 34 fathers who were not non-drinkers, $9(26.5 \%)$ reported increased alcohol consumption after the loss. Out of 38 fathers $7(18.4 \%)$ reported that they had used prescribed drugs specifically to enable them to cope after the stillbirth. Three fathers $(7.9 \%)$ reported using illegal drugs. Nearly half of the fathers $(47.4 \%)$ had received some form of professional help from hospital counsellors, ministers of religion or other healthcare professionals, and five fathers $(13.2 \%)$ had been in contact with the voluntary self-help group Stillbirth and Neonatal Death Society (SANDS). A substantial proportion of the fathers $(39.5 \%$ of fathers $v .42 .1 \%$ of mothers) would have welcomed some form of further support (other than that of family and friends) after the stillbirth.

\section{Levels of psychological symptoms in mothers}

As in our previous study (Hughes et al, 1999), mothers who had experienced a stillbirth had significantly higher levels

Table 3 Index group within-couple analysis

\begin{tabular}{lccccc}
\hline & $\begin{array}{c}\text { Couples } \\
(n)\end{array}$ & $\begin{array}{c}\text { Mean } \\
\text { differencel }\end{array}$ & $95 \% \mathrm{Cl}$ & $\begin{array}{c}\text { Significance } \\
\text { (paired } t \text {-test) }\end{array}$ & $\begin{array}{c}\text { Correlation } \\
\text { (significance) }\end{array}$ \\
\hline $\begin{array}{l}\text { Antenatal PTSD } \\
\text { symptom severity score }\end{array}$ & 30 & -6.63 & -14.68 to I.4I & 0.102 & $0.429(0.018)$ \\
$\begin{array}{l}\text { Antenatal Spielberger } \\
\text { state score }\end{array}$ & 33 & -4.42 & -9.24 to 0.39 & 0.070 & $0.413(0.017)$ \\
$\begin{array}{l}\text { Antenatal Spielberger } \\
\text { trait score }\end{array}$ & 32 & -1.41 & -5.43 to 2.62 & 0.482 & $0.341(0.056)$ \\
$\begin{array}{l}\text { I-year Spielberger state } \\
\text { score }\end{array}$ & 30 & -2.57 & -7.05 to 1.92 & 0.251 & $0.309(0.096)$ \\
$\begin{array}{l}\text { I-year Spielberger trait } \\
\text { score }\end{array}$ & 30 & -2.13 & -7.02 to 2.76 & 0.380 & $0.158(0.403)$ \\
I-year BDI score & 31 & -2.35 & -4.72 to 2.64 & 0.052 & $0.209(0.259)$ \\
\hline
\end{tabular}

PTSD, post-traumatic stress disorder; BDI, Beck Depression Inventory.

I. Difference is equal to fathers' scores minus mothers' scores. Thus negative scores indicate higher levels in the mothers.

of depression and anxiety than controls across all assessments and at all time points, with the exception of depression scores at the 6-month assessment. We also replicated the finding of noteworthy levels of stillbirth-related PTSD in mothers. The prevalence of PTSD in response to the stillbirth was similar for fathers and mothers at both the antenatal assessment and the 1-year follow-up. Six of the mothers $(18.8 \%)$ met the criteria for current PTSD during pregnancy but, as with the fathers, symptoms had remitted in all but one mother by 1 year post-partum following the birth of a live baby.

\section{Comparison between mothers' and fathers' symptom levels in the index group}

When we compared mothers' and fathers' symptom levels within samples on the same measures (BDI depression scores at 1-year follow-up, Spielberger state and trait anxiety scores both antenatally and at 1-year follow-up, and PTSD symptom severity score antenatally), we found that mothers had higher levels of psychological symptoms than fathers at every assessment, although the difference did not reach the level of significance (see Table 3). We also wanted to determine whether there was any correlation between partners' (i.e. mothers' and fathers') scores - that is, whether both partners within a couple responded in similar ways to their trauma, or whether within-couple scores were unrelated. In fact, within-pair correlations were not strong, only reaching significance in relation to antenatal PTSD symptom severity scores and Spielberger state anxiety scores (see Table 3 ).

\section{Factors associated with psychological morbidity in fathers in the index group}

As with mothers, there was no association between fathers' levels of psychological symptoms in the pregnancy following stillbirth and socio-demographic factors (age, ethnicity, income or level of education). There was also no association with the presence of other children in the family.

Using MANOVA, we then looked at two sets of dichotomous factors. First, we examined background factors that have 
been identified as being associated with poorer outcome in mothers (history of treatment for psychological symptoms, time period between loss and becoming pregnant again $(<12$ months or $>12$ months), whether or not the father felt that he received emotional support from his partner and family). Secondly, we examined factors connected with the loss itself (the gestation of the lost pregnancy (second or third trimester), whether or not the father had seen the dead infant). Possibly because of the small numbers in each group, none of these independent variables in fathers were found to be significantly associated with depression, anxiety or PTSD symptom scores at the antenatal assessment. However, Table 4 shows a consistent trend towards findings being similar in fathers to those that have been reported in mothers, with a worse outcome occurring if fathers had a history of treatment for psychological symptoms, if they had not felt well supported by their partner and family at the time of the loss, if the loss had occurred in the third trimester, or if they had seen their dead infant. Interestingly, the finding in relation to the time interval between a stillbirth and conceiving again showed a trend in the opposite direction in fathers, with higher depression and anxiety scores occurring where there had been a longer delay (more than 1 year). The Pearson correlation between the time interval in months and antenatal trait anxiety in fathers was $0.455(P=0.007)$. For mothers in the present study, again there was a slight trend towards higher trait anxiety and PTSD scores if the pregnancy under investigation (i.e. that following a stillbirth) had been delayed. This finding runs counter to the results of other reports.

\section{DISCUSSION}

There are good reasons for postulating that stillbirth may have an effect on fathers that is comparable to the effect on mothers. For both parents, the stillbirth may represent the loss of dreams and hopes that were invested in the prospect of parenthood (de Montigny et al, 1999). Moreover, because of a tendency to focus on the experience of mothers, the severity of the loss for the father may not be fully recognised (Peppers \& Knapp, 1980). Fathers may suffer from a social expectation that their primary role is to support their partner (de Montigny et al, 1999) or to remain strong in the face of their partner's grief (Kennell et al, 1970).
A systematic evaluation of the impact of stillbirth on fathers has the potential to identify a group that experiences distressing but treatable symptoms, as well as to inform cultural knowledge and behaviour with regard to bereaved fathers.

When we reviewed the original data in the literature specific to the psychological effects of perinatal death (stillbirth or neonatal death) on fathers, we found that the published studies vary both in their emphasis and in quality of design, and most of them have serious methodological weaknesses. Many studies had to be excluded because they conflate different types of loss (e.g. miscarriage, stillbirth, neonatal death and sudden infant death syndrome) without separating the results by loss category. The studies also vary in the time interval since the loss (e.g. 2 months in Zeanah et al, 1995, and between 2 months and 5 years in Worth, 1997). Many studies (both qualitative and quantitative) have problems with generalisability arising from population bias, sampling bias and response bias. For example, Theut et al (1989, 1990), Worth (1997) and DeFrain et al (1991) used volunteer samples, and one American group (Hughes \& Page-Liberman, 1989) identified some of their sample from

Table 4 Predictor variables and outcome scores for fathers

\begin{tabular}{|c|c|c|c|c|c|c|c|c|c|}
\hline & \multirow[t]{3}{*}{$n$} & \multicolumn{8}{|c|}{ Fathers' antenatal scores } \\
\hline & & \multicolumn{2}{|c|}{ BDI } & \multicolumn{2}{|c|}{ Spielberger state } & \multicolumn{2}{|c|}{ Spielberger trait } & \multicolumn{2}{|c|}{ PTSD } \\
\hline & & Mean & s.d. & Mean & s.d. & Mean & s.d. & Mean & s.d. \\
\hline \multicolumn{10}{|c|}{ History of psychological symptoms } \\
\hline Yes & 7 & 10.57 & 11.10 & 40.29 & 14.36 & 41.86 & 13.27 & 60.67 & 25.12 \\
\hline No & 27 & 4.89 & 4.36 & 36.14 & 11.07 & 36.96 & 8.55 & 39.31 & 14.96 \\
\hline \multicolumn{10}{|l|}{ Loss to conception } \\
\hline$\geqslant$ I year & II & 7.9 & 9.48 & 38.2 & 13.56 & 41.9 & 11.09 & 42.5 & 19.22 \\
\hline$<$ I year & 23 & 5.2 & 4.57 & 36.4 & 11.00 & 36.1 & 8.55 & 43.7 & 19.07 \\
\hline \multicolumn{10}{|l|}{ Partner supportive } \\
\hline No/uncertain & 8 & 11.9 & 9.36 & 43.6 & 12.14 & 45.0 & II.I5 & 55.1 & 23.82 \\
\hline Yes & 25 & 4.3 & 4.31 & 34.6 & II.0I & 35.8 & 8.42 & 40.6 & 16.30 \\
\hline \multicolumn{10}{|l|}{ Family supportive } \\
\hline No/uncertain & 9 & 9.9 & 9.79 & 37.3 & 13.40 & 39.9 & 14.66 & 49.1 & 23.89 \\
\hline Yes & 25 & 4.7 & 4.41 & 36.8 & 11.33 & 37.3 & 7.44 & 41.0 & 16.50 \\
\hline Third trimester loss & 20 & 7.2 & 7.49 & 40.5 & 12.07 & 40.2 & 9.22 & 44.1 & 19.06 \\
\hline Second trimester loss & 14 & 4.5 & 4.72 & 31.7 & 9.14 & 34.4 & 9.66 & 42.1 & 19.18 \\
\hline \multicolumn{10}{|l|}{ Saw dead infant } \\
\hline Yes & 30 & 6.7 & 6.73 & 37.5 & 11.88 & 38.8 & 9.95 & 44.4 & 19.58 \\
\hline No & 4 & 1.5 & 1.29 & 32.8 & 10.53 & 31.5 & 3.11 & 36.0 & 11.17 \\
\hline
\end{tabular}

BDI, Beck Depression Inventory; PTSD, post-traumatic stress disorder. 
support groups. This is important because, as Toedter et al (2001) have reported, significantly higher grief scores were found in studies that recruited participants from support groups and self-selected populations rather than from medical sources. Two studies (Dyregrov \& Matthiesen, 1987; Samuelsson et al, 2001) systematically excluded individuals on the basis of adverse social or family situations (which were not described). Social class is an important area of potential bias, and is relevant in studies where researchers have deliberately included only a homogenous group (Helmrath \& Steinitz, 1978), or where responders are demographically different from non-responders. Most of the papers that have addressed such demographic differences have not considered social class, with the exception of a study by Zeanah et al (1995), who found that non-responders were significantly more likely to be from a lower social class. Small sample size also limits generalisability. The majority of the papers that we reviewed did not report power calculations for their sample sizes. The exception was the series of papers by Vance, Foster, Najman and colleagues (Vance et al, 1991, 1994, 1995a,b; Najman et al, 1993), in which adequate sample sizes were recorded. However, a large proportion of the participants in that cohort dropped out or were lost to follow-up at 6 months and 8 months, and were excluded from the analysis (Najman et al, 1993; Vance et al, 1995a), thus potentially skewing the reported findings.

Most of the studies (Kimble, 1991; Worth, 1997) did not have a control group, although some researchers compared different types of loss, or compared the effects on fathers with those on mothers. The outcome measures varied. Where a qualitative approach was used, fathers reported feelings of grief and described their role as being a social support to their partner. With the exception of the study by Worth (1997), these research findings were limited by a lack of measures to ensure reliability. Quantitative studies tend to measure grief responses, depression and anxiety. To our knowledge, no studies to date have measured the development of PTSD in fathers. Other possible limitations of such research include the use of instruments not commonly employed to measure the outcomes under investigation (for example, Vance and colleagues used sub-scales of the Delusions Symptoms States Inventory to measure affective symptoms; Foulds $\&$
Bedford, 1978), and a tendency not to report $P$ values or confidence intervals.

Despite these limitations, the consistency of certain findings and observations suggests that many fathers do experience grief after a perinatal loss, including feelings of shock, anger, emptiness, helplessness and loneliness (e.g. Kimble, 1991; Zeanah et al, 1995; Worth, 1997; Samuelsson et al, 2001). Symptoms of depression and anxiety have also been described (Vance et al, 1995a,b). The expected social role of fathers as a support to their partner (Helmrath \& Steinitz, 1978) may partly explain the observation that the grief reactions of fathers tend to be less intense than those of mothers. Levels of marital dissatisfaction are reported to be higher in bereaved fathers than in controls (Najman et al, 1993), but there are no data on whether relationships survive intact in the wake of the loss.

This paper forms part of a series in which our research group is investigating the effects of a previous stillbirth on families. As noted above, we have already investigated psychological symptoms in mothers (Hughes et al, 1999; Turton et al, 2001). We have also reported that unresolved mourning for the lost infant is prevalent in mothers during the next pregnancy (Hughes et al, 2004), and that this is associated with an increase in insecure disorganised attachment in infants born subsequent to a stillbirth (Hughes et al, 2001). We have also reported on the association between the psychosocial management of stillbirth and adverse outcome for the mother and the next-born child (Hughes et al, 2002). We are currently writing up a 7-year follow-up study of mothers and next-born children after a stillbirth.

In the present case-control cohort study we compared fathers whose partners' previous pregnancy had ended in stillbirth with both their partners and non-bereaved fathers. The index group consisted of couples who were expecting a child and whose last pregnancy had ended in spontaneous loss after 20 weeks' gestation. Although our primary interest was in fathers, it would have been insensitive to exclude mothers from a study of the psychological impact of previous stillbirth on the next pregnancy. We chose a 20 -week cut-off point because clinicians generally regard a loss in the second half of pregnancy as representing the loss of a child to the parents. All of the parents were over 20 years of age, had a singleton pregnancy and spoke enough English for them to be interviewed. The control group consisted of couples who had not experienced a stillbirth but who were otherwise pair-matched (from the mothers' obstetric records) as closely as possible with regard to age, ethnicity, obstetric history, presence of children in the family, and socio-economic status according to occupation. We excluded couples antenatally if either parent was currently receiving treatment for acute physical or mental illness.

\section{Difficulties with recruitment of male participants}

We experienced many more recruitment problems in this study than in our previous investigation of the psychological effects of a stillbirth on mothers, in which $86 \%$ of mothers consented to take part. Although it was not always possible to identify the reason or individual responsible for a couple's refusal to participate, it was our strong impression that fathers were much more likely to refuse to take part than mothers. This was not simply attributable to the difficulty in finding a suitable appointment time (we were always ready to make appointments at times convenient to participants, including evenings and weekends). It seemed that we were caught up in a more widespread problem in recruiting men to psychological or social research, which has been noted previously (Lewis et al, 1989). This difficulty may explain why other studies of parents have involved far fewer fathers than mothers (DeFrain et al, 1991; Zeanah et al, 1995), and it may reflect a cultural belief that men are less willing to talk about their feelings than women. This belief may have been exacerbated in a study related to pregnancy, where men identify themselves as less involved, and by the common assumption that a pregnancy loss has a greater impact on mothers because of their physical involvement in carrying the baby (Theut et al, 1988). Whatever the reason, the difficulty with recruitment of male participants is a problem in psychological research involving men, and further work is needed to identify the factors that impede collaboration and to find ways of overcoming those factors.

\section{The importance and neglect of fathers in stillbirth research}

This study has confirmed that the pregnancy following a stillbirth is a particularly 
stressful time for parents, and that although fathers show lower levels of psychological morbidity than their partners, they are still vulnerable to significant levels of distressing symptoms, particularly anxiety and PTSD. Reassuringly, it appears that these symptoms largely remit after the birth of a live child, although mothers continue to be more vulnerable than fathers to ongoing psychological morbidity. This finding is consistent with some previous research, but runs counter to the results of other studies which have suggested that although mothers' grief may be more intense in the short term, fathers' scores do not decline as much as the scores of mothers over time (Stinson et al, 1992).

Our findings also suggest that there is a tendency for parents' levels of symptoms to run in tandem rather than for one of the partners to 'carry' the burden of symptomatic distress for both parents, or for one of the partners (typically the father) to feel that they have to deny their grief in order to remain strong in the face of the other's distress.

\section{Factors that have a protective effect and factors that increase risk}

Previous research has identified factors that appear to be associated with a more adverse outcome in mothers, in particular psychiatric symptoms before the loss (Janssen et al, 1997), early subsequent pregnancy (Hughes et al, 1999), longer gestation (Theut et al, 1989) less support from partners or family (Turton et al, 2001), and physical contact with the dead infant (Hughes et al, 2002). This study extends and provides some additional support for these findings. The finding that parental contact with the dead infant appears to increase risk is sensitive. Not only does it run counter to existing models of 'good practice', but also our interviews with parents confirmed that those parents who did have such contact greatly valued the opportunity they had to spend time with their dead infant, and would not willingly have foregone the experience. It is possible that such contact intensifies an attachment that no parent could regret. However, given the evidence which suggests that parents who do have such contact are more rather than less vulnerable to distressing symptoms in their next pregnancy, we believe that clinicians should be cautious about advocating its benefits. The parents in our study who did not see their dead infant had no regrets

\section{CLINICAL IMPLICATIONS}

Fathers' vulnerability to anxiety and post-traumatic stress disorder during a pregnancy subsequent to a stillbirth should be recognised.

- Fathers need support in their own right, rather than simply as an adjunct to their partner.

- Fathers may have different needs from their partner with regard to the timing of a subsequent pregnancy.

\section{LIMITATIONS}

- This study illustrates the major difficulties that are encountered when recruiting men to research related to the psychological aspects of pregnancy and pregnancy loss.

- Our sample size is limited, which reduces the statistical power of our findings.

- Our sample is biased towards affluent White families.

PENELOPE TURTON, PhD, WILLIAM BADENHORST, MRCPsych, PATRICIA HUGHES, MD, FRCPsych, JULIA WARD, BSc, SAMANTHA RICHES, BSc, SARAH WHITE, BSc, MSc, Division of Mental Health, St George's University of London, London, UK

Correspondence: Dr Penelope Turton, Division of Mental Health, St George's University of London, London SWI7 0RE,UK. E-mail: pturton@sgul.ac.uk

(First received I5 June 2004, final revision 4 March 2005, accepted 14 March 2005)

either. The solution that is usually proposed for this problem is 'parental choice'. However, the choice of whether or not to see and hold their dead infant takes place in a social and cultural context that currently emphasises the importance of acknowledging and confronting feelings (even negative ones) rather than suppressing or avoiding them. In such a culture it may be difficult for parents to decline the invitation to spend time with their dead infant. Perhaps both society and parents believe that some degree of psychological morbidity is a price worth paying for such a highly valued experience. Further research on this important topic in a broader cultural context is urgently needed.

It is interesting that, for the fathers in our study, there was a trend for better outcome to be associated with conceiving again within a year of the stillbirth, contrary to previous research findings in relation to mothers (Theut et al, 1990; Hughes et al, 1999; Rich, 2000). It is possible that these are chance findings, but it is also possible that fathers and mothers have different needs in relation to this decision. Whereas mothers need time to mourn and recover before becoming pregnant again, fathers' levels of depression and anxiety may increase as more time elapses before there is a real prospect of becoming a parent again. If this is the case, then there are implications for the advice that parents should be given about the timing of a subsequent pregnancy in the best interests of both partners.

\section{REFERENCES}

American Psychiatric Association (1987) Diagnostic and Statistical Manual of Mental Disorders (3rd edn revised) (DSM-III-R). Washington, DC: APA.

Beck, A. T., Ward, C. H., Mendelson, M., et al (1961) An inventory for measuring depression. Archives of General Psychiatry, 4, 56I-57I.

CACI (2003) Wealth of the Nation Survey Report London: $\mathrm{CACl}$.

Cox, J. L., Holden, J. M. \& Sagovsky, R. (1987) Detection of postnatal depression. Development of the 10-item Edinburgh Postnatal Depression Scale. British Journal of Psychiatry, I50, 782-786.

DeFrain, J., Martens, L., Stork, J., et al (1991) The psychological effects of a stillbirth on surviving family members. Journal of Death and Dying, 22, 8I-108.

de Montigny, F., Beaudet, R. N. \& Dumas, L. (1999) A baby has died: the impact of perinatal loss on family 
social networks. Journal of Obstetric, Gynecologic and Neonatal Nursing, 28, $151-156$.

Dyregrov, A. \& Matthiesen, S. B. (1987) Anxiety and vulnerability in parents following the death of an infant. Scandinavian Journal of Psychology, 28, 16-25.

Foulds, G. A. \& Bedford, A. (1978) DelusionsSymptoms-States Inventory of Anxiety and Depression. Windsor: National Foundation of Educational Research.

Helmrath, T. \& Steinitz, E. M. (1978) Death of an infant: parental grieving and the failure of social support. Journal of Family Practice, 6, 785-790.

Hughes, C. B. \& Page-Lieberman, J. (1989) Fathers experiencing a perinatal loss. Death Studies, I3, 537-556.

Hughes, P., Turton, P. \& Evans, C. D. H. (1999) Stillbirth as a risk factor for anxiety and depression in the next pregnancy: does time since loss make a difference? BMJ, 318, 172I-1724.

Hughes, P., Turton, P., Hopper, E., et al (200I) Disorganised attachment behaviour among infants born subsequent to stillbirth. Journal of Child Psychology and Psychiatry, 42, 791-801.

Hughes, P., Turton, P., Hopper, E., et al (2002) Assessment of good practice guidelines in the psychosocial care of mothers after stillbirth: a cohort study. Lancet, 360, 114-118.

Hughes, P., Turton, P., Hopper, E., et al (2004) Factors associated with the unresolved classification of the adult attachment interview in the pregnancy following a stillbirth. Development and Psychopathology, 16, 215-230.

Janssen, H. J. E. M., Cuisinier, M. C. J., de Graauw, K. P., et al (1997) A prospective study of risk factors predicting grief intensity following pregnancy loss. Archives of General Psychiatry, 54, 56-6I.

Keane, T. M., Malloy, P. F. \& Fairbank, J. A. (1984) Empirical development of an MMPI subscale for the assessment of combat-related post-traumatic stress disorder. Journal of Consulting and Clinical Psychology, 52 888-891.

Kennell, J. H., Slyter, H. \& Klaus, M. H. (1970) The mourning response of parents to the death of a newborn infant. New England Journal of Medicine, 283, 344-349.
Kimble, D. L. (199I) Neonatal death: a descriptive study of fathers' experiences. Neonatal Network Journal of Neonatal Nursing, 9, 45-50.

Lewis, R. J., Winstead, B. \& Derlega, V. J. (1989) Gender differences in volunteering for friendship research. Journal of Social Behaviour and Personality, 4 , 623-632.

Melcalfe, M. \& Goldman, E. (1965) Validation of an inventory for measuring depression. British Journal of Psychiatry, III, 240-242.

Murray, D. \& Cox, J. (1990) Screening for depression during pregnancy with the Edinburgh Postnatal Depression Scale (EPDS). Journal of Reproductive and Infant Psychology, 8, 99-107.

Najman, J. M., Vance, J. C., Boyle, F., et al (1993) The impact of a child death on marital adjustment. Social Science and Medicine, 37, 1005-1010.

Peppers, L. G. \& Knapp, R. J. (1980) Maternal reactions to involuntary fetal/infant death. Psychiatry: Journal for the Study of Interpersonal Processes, 43, 155-159.

Rich, D. E. (2000) The impact of postpregnancy loss services on grief outcome: integrating research and practice in the design of perinatal bereavement programs. Illness, Crisis and Loss, 8, 244-264.

Rust, J., Bennun, I., Crowe, M., et al (1988) The Golombok Rust Inventory of Marital Satisfaction (GRIMS). Windsor: NFER-Nelson.

Samuelsson, M., Radestad, I. \& Segesten, K. (200I) A waste of life: fathers' experience of losing a child before birth. Birth, 28, 124-130.

Spielberger, C. D., Gorsuch, R. L. \& Lushene, R. (1970) Test for the State-Trait Anxiety Inventory. Palo Alto, CA: Consulting Psychologists Press.

Stinson, K. M., Lasker, J., Lohmann, J., et al (1992) Parents' grief following pregnancy loss: a comparison of mothers and fathers. Family Relations, 41, 218-223.

Theut, S. K., Pedersen, F. A. \& Zaslow, M. J. (1988) Pregnancy subsequent to perinatal loss: parental anxiety and depression. Journal of the American Academy of Child and Adolescent Psychiatry, 27, 289-292.
Theut, S. K., Pedersen, F. A., Zaslow, M. J., et al (1989) Perinatal loss and parental bereavement. American Journal of Psychiatry, 146, 635-639.

Theut, S. K., Zaslow, M. J., Rabinovich, B. A., et al (1990) Resolution of parental bereavement after a perinatal loss. Journal of the American Academy of Child and Adolescent Psychiatry, 29, 521-525.

Toedter, L. J., Lasker, J. N. \& Janssen, H. J. E. M (200I) International comparison of studies using the Perinatal Grief Scale: a decade of research on pregnancy loss. Death Studies, 25, 205-228.

Turton, P., Hughes, P., Evans, C. D. H., et al (2001) The incidence and significance of post-traumatic stress disorder in the pregnancy after stillbirth. British Journal of Psychiatry, 178, 556-560.

Vance, J. C., Foster, W. J., Najman, J. M., et al (1991) Early parental responses to sudden infant death, stillbirth or neonatal death. Medical Journal of Australia, 155, 292-297.

Vance, J. C., Najman, J. M., Boyle, F. M., et al (1994) Alcohol and drug usage in parents soon after stillbirth, neonatal death or SIDS. Journal of Paediatrics and Child Health, 30, 269-272.

Vance, J. C., Najman, J. M., Thearle, M. J., et al (1995a) Psychological changes in parents eight months after the loss of an infant from stillbirth, neonatal death or sudden infant death syndrome - a longitudinal study. Pediatrics, 96, 933-938.

Vance, J. C., Boyle, F. M., Najman, J. M., et al (1995b) Gender differences in parental psychological distress following perinatal death or sudden infant death syndrome. British Journal of Psychiatry, 167, 806-8II.

Watson, C. G., Juba, M. P., Manifold, V., et al (199I) The PTSD Interview: rationale, description, reliability and concurrent validity of a DSM-III-based technique. Journal of Clinical Psychology, 47, 179-188.

Worth, N. J. (1997) Becoming a father to a stillborn child. Clinical Nursing Research, 6, 7I-89.

Zeanah, C. H., Danis, B., Hirshberg, L., et al (1995) Initial adaptation in mothers and fathers following perinatal loss. Infant Mental Health Journal, I6, 80-93. 